\title{
An ejectable electrode in a syringe holder for lesioning mice
}

\author{
CHRISTOPHER CHERRY and BASIL E. ELEFTHERIOU \\ The Jackson Laboratory, Bar Harbor, Maine 04609
}

\begin{abstract}
A syringe holder for long fine electrodes is described. The device was designed for use in lesioning mice. The holder is easily constructed from a disposable syringe by simply adapting the plunger for grasping the electrode and for connecting to a lesion maker.
\end{abstract}

Advances in surgical procedures in recent years allow greater use of the mouse in neurobehavioral and neurophysiological research. A stereotaxic atlas of the mouse brain (Montemurrow \& Dukelow, 1972; Slotnik \& Essman, 1964) and an atlas of the forebrain of the deermouse have been developed (Eleftheriou \& Zolovick, 1965). Refinements have been made in stereotaxic apparatus in an effort to avoid damage to the auditory meatus of the mouse that may result from using conventional ear bars. Thus, a stereotaxic headholder for small animals, in which the head is positioned by needles tightened onto the skull, has been designed (Heimer, Kuika, Larson, \& Nordstrom, 1971). With another headholder, the mouse head is clamped between the nasal bones and the hard palate, which ensures consistent positioning for electrode placement (Slotnik, 1972). The development of surgical techniques includes a procedure for chronic implantation of electrodes (Zornetzer, 1970) and a simple device for producing $\mathrm{dc}$ lesions using enamel insulated phonograph needles mounted in a Plexiglas block (Greenstein \& Glick, 1972). Other ways of producing lesions in mice include the use of enamel insulated stainless steel insect pins (Carlson, Carter, \& Vallante, 1972) and varnish coated stainless steel wire (Eleftheriou \& Zolovick, 1967).

This report describes an ejectable electrode in a syringe holder designed for use in lesioning mice. As shown in Figure 1, the assembled unit consists of a length of fine enamel coated wire pressed up into a short piece of tubing in the tip of the plunger. A length of wire soldered to the tubing is threaded through holes drilled in the plunger. A plug is fitted on the end of the wire for connection to a lesion maker. Once the complete unit is mounted in a stereotaxic instrument, as much electrode as needed can be pushed out of the needle. The needle provides only support to the electrode and does not come in contact with the brain. As the electrode is used, the tip can be trimmed and more electrode pushed out.

This work was supported by Grant HD 05860 from the National Institute of Child Health and Human Development. The Jackson Laboratory is fully accredited by the American Association for Accreditation of Laboratory Animal Care.

\section{MATERIALS AND METHODS}

As shown in Figure 1, the plunger of a 1-cc disposable syringe Becton-Dickinson) is removed from the barrel. The rubber seal at the tip of the plunger is removed and the plunger is carefully drilled out as indicated in the enlarged view of the plunger to accommodate the connecting wire. With a No. 64 wire gauge drill (Brookstone Company, Peterborough, New Hampshire) in an adapter chuck (Brookstone), the plunger tip is slowly hand drilled as shown in Figure 1. Next, a 20-ga disposable needle (Becton-Dickinson), is heated with an alcohol lamp or candle and a tapered crimp is formed in the center with a hammer. The crimp is tested with a piece of 30-ga full hard temper round wire (Silverman's, Arch Street, Philadephia, Pennsylvania). A short piece of wire is slipped into the needle up to the crimp and lightly tapped into the crimped part. The crimped needle should pinch and hold the wire tight. When the crimp holds, the needle is cut into a $10-\mathrm{mm}$ piece with the crimp at about the center. Then, a 24-in. piece of Alpha 1850 Type B Size 32 hook-up wire (Newark Electronics) is soldered into the end of the tubing that will be inserted into the plunger. The wire is then threaded through the plunger and the tubing is pushed up into the plunger tip until it is held securely. A small hole is then cut in the rubber

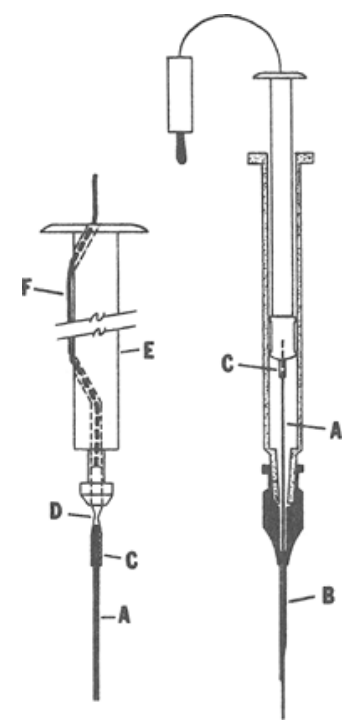

Figure 1. Detailed view of plunger construction and cutaway view of assembled holder. (A) electrode. (B) needle guide. (C) 20-ga tubing. (D) crimped section of tubing. (E) plunger body. (F) Size 32 hook-up wire. 
seal, which is slipped over the tubing and back onto the plunger tip. The wire is then pulled tight and taped to the side of the plunger. Finally, a banana plug is attached to the other end of the wire for connecting to a lesion maker.

\section{RESULTS AND DISCUSSION}

The electrodes are made from 30-ga wire (Silverman's cut to approximately $10 \mathrm{~cm}$ ). Before coating, the cut pieces should be cleaned of residue by sanding with fine steel wool or dipped into acetone. Several pieces may be coated at a time by fitting them into a small cork. The electrodes are then dipped in Epoxylite 600-M (Epoxylite Corporation, Buffalo, New York) or similar insulating varnish and baked dry at about $100^{\circ} \mathrm{C}$. It is especially important the varnish coating be smooth because of the close fit the electrodes will make in the needle. For this reason, it is suggested that the electrodes not be coated by hand, but' mechanically, using a stereotaxic manipulator or some other smoothly working device. After three or four coats of varnish are applied, the electrodes are clipped off smoothly at the tip and tested for leakage. The plunger is replaced in the barrel and with a 24-ga 1-in. needle (Becton-Dickinson) on the syringe, an electrode is slipped through the needle and into the retaining tube in the plunger. A few light taps should secure the electrode, and the plunger can be drawn up until only a few millimeters of the electrode are protruding from the needle. The holder is then mounted onto a stereotaxic manipulator. As the electrode is used, the plunger is simply pushed down and the used part of the electrode is clipped off.

A holder has been used in this laboratory for making direct current lesions in mice. A total of 23 animals were lesioned, and examination of the brains following histological preparation revealed that 19 animals received bilateral lesions confined to the amygdala, the designated area.

In conclusion, it appears that this design provides the experimenter working with small animals such as the mouse with two distinct advantages: a rigid guide needle that helps to maintain the vertical alignment of the electrode as it passes into the brain, and a syringe that can be used as a reservoir for much longer electrodes.

\section{REFERENCES}

Carlson, N. R., Carter, E. N., \& Vallante, M., Runway alternation and discrimination of mice with limbic lesions, Journal of Comparative and Physiological Psychology, 1972, 78, 91-101.

Eleftheriou, B. E., \& Zolovick, A. J., The forebrain of the deer mouse in stereotaxic coordinates, Kansas Argicultural Experimental Bulletin, No. 146 (1965) whole.

Eleftheriou, B. E. \& Zolovick, A. J.. Effects of amygdaloid lesions on plasma and pituitary levels of luteinizing hormone, Journal of Reproduction and Fertility, 1967, 14, 33-37.

Greenstein, S., \& Glick, S. D., A simple procedure for making stereotaxic lesions in the mouse, Physiology and Behavior, $1972,8,781-782$.

Heimer, L., Kuika, V., Larson, K., \& Nordstrom, E., A headholder for stereotaxic operations of small laboratory animals, Physiology and Behavior, 1971, 7, 263-264.

Montemurxo, D. G., \& Dukelow, R. H., Stereotaxic atlas of the diencephalon of the mouse. Futura Publishing Company, Mt. Kisco, N, Y : 1972.

Slotnik, B, M., Stereotaxic surgical techniques for the mouse. Physiology and Behavior, 1972, 8, 139-142.

Slotnik, B, M., \& Essman, W. G., A stereotaxic atlas of the mouse brain. American Zoologist, 1964, 4, 288.

Zornetzer, L. A simple and reliable chronic brain implantation technique for the mouse. Physiology and Behavior, 1970, 5, 1197-1199.

(Received for publication September 13, 1974, revision accepted September $25,1974$. ) 